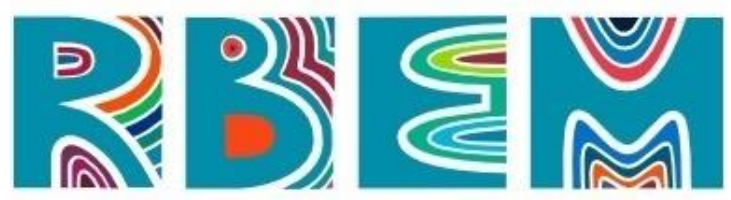

REVISTA BAIANA dE EDUCAÇÃo MATEMÁtica

ARTIGO

https://doi.org/10.47207/rbem.v2i01.12389

\title{
Condições e restrições do estágio supervisionado no ensino remoto, no curso de Matemática - Licenciatura Da UFMS
}

\author{
BURIGATO, Sonia Maria Monteiro da Silva \\ Universidade Federal do Mato Grosso do Sul (UFMS). Doutora em Educação Matemática. ORCID: \\ https://orcid.org/0000-0001-8403-6032. E-mail: sonia.burigato@ufms.br \\ SANTOS, Cintia Melo dos \\ Universidade Federal da Grande Dourados (UFGD). Doutora em Educação Matemática. ORCID \\ https://orcid.org/0000-0003-2121-3120. E-mail: cintisantos@ufgd.edu.br.
}

\begin{abstract}
Resumo: O objetivo principal deste artigo é apresentar algumas discussões sobre condições e restrições, segundo Chevallard, para o desenvolvimento do Estágio Supervisionado durante o ensino remoto. Para tanto, fizemos o estudo de uma turma da disciplina de Estágio Supervisionado II, do Curso de Matemática - Licenciatura de uma universidade pública. Essa disciplina ocorreu no modelo de ensino remoto, situação totalmente atípica para uma disciplina que busca inserir o acadêmico em seu futuro ambiente profissional. Todavia, foi uma maneira de lidar com o isolamento social imposto pela pandemia provocada pelo Covid-19. Desse modo, buscamos nos relatórios finais, apresentados para conclusão dessa disciplina, elementos para analisarmos as condições e restrições para a realização da disciplina de Estágio Supervisionado II no modelo de ensino remoto. Esses acadêmicos eram de um curso presencial e tiveram de lidar com essas mudanças logo no início desse cenário pandêmico. Em nossas análises, percebemos o quantos as restrições impostas, pelo modelo de ensino remoto, criaram algumas condições para o desenvolvimento do estágio. De modo que estes puderam vivenciar algumas experiências, como análise dos Projetos Políticos Pedagógico (PPP) das escolas, dos livros didáticos e, além disso, a simulação de aulas síncronas via plataforma meet entre os próprios acadêmicos. O que possibilitou que experimentassem o componente curricular do Estágio Supervisionado em um contexto totalmente atípico.
\end{abstract}

Palavras-chave: Formação Inicial. Condições e Restrições. Estágio Supervisionado.

\section{Conditions and restrictions of the supervised internship in remote education, in the Mathematics course - degree at UFMS}

\begin{abstract}
The main objective of this article is to present some discussions about the conditions and restrictions, according to Chevallard, for the development of the Supervised Internship during remote learning. Therefore, we did the study of a class of the discipline Mandatory Internship II, from the Mathematics Course - Licentiate of a public university. This discipline occurred in the remote teaching model, a completely atypical situation for a discipline that seeks to insert the academic into their future professional environment. However, it was a way to deal with the social isolation imposed by the pandemic caused by Covid-19. In this way, we searched in the final reports, presented for the conclusion of this discipline, elements to analyze the conditions and restrictions for the realization of this internship discipline in the remote teaching model. These academics were from a classroom course and had to deal with these changes right at the beginning of this pandemic scenario. In our
\end{abstract}




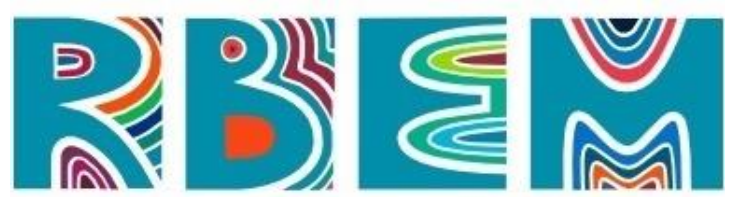

REVISTA BAIANA DE EDUCAÇÃO MATEMÁTICA

analysis, we realized how much the restrictions imposed by the remote learning model created some conditions for the development of the internship. So that, they were able to experience some experiences, such as: analysis of Political Pedagogical Projects (PPP) of schools, textbooks and, in addition, the simulation of synchronous classes via the meet platform among the academics themselves. What made it possible for them to experience the curricular component of the Supervised Internship in a totally atypical context.

Keywords: Initial formation. Conditions and Restrictions. Supervised internship.

\section{Condiciones y restricciones de la práctica supervisada en educación a distancia, en el curso de Matemáticas - Licenciatura en la UFMS}

Resumen: El objetivo principal de este artículo es presentar algunas discusiones sobre las condiciones y restricciones, según Chevallard, para el desarrollo de la Pasantía Supervisada durante la enseñanza a distancia. Para ello, estudiamos una clase de la asignatura de Pasantía Obligatoria II, del Curso de Matemáticas - Licenciatura en una universidad pública. Esta disciplina tuvo lugar en el modelo de enseñanza a distancia, una situación completamente atípica para una disciplina que busca insertar al académico en su futuro entorno profesional. Sin embargo, fue una forma de lidiar con el aislamiento social impuesto por la pandemia provocada por Covid-19. Así, se buscaron en los informes finales presentados para completar esta disciplina, elementos para analizar las condiciones y restricciones para la realización de esta disciplina de prácticas en el modelo de enseñanza a distancia. Estos académicos eran de un curso presencial y tuvieron que lidiar con estos cambios al principio de este escenario de pandemia. En nuestro análisis, nos dimos cuenta de cuánto las restricciones impuestas por el modelo de enseñanza a distancia crearon algunas condiciones para el desarrollo de la pasantía. Así, pudieron vivir algunas experiencias, como: análisis de Proyectos Políticos Pedagógicos (PPP) de las escuelas, de los libros didácticos y, además, la simulación de clases sincrónicas a través de la plataforma meet entre los propios académicos. Lo que les permitió vivir el componente curricular de la Práctica Supervisada en un contexto totalmente atípico.

Palavras-Clave: Formación inicial. Condiciones y restricciones. Pasantía supervisada.

\section{Introdução}

A nossa sociedade tem visto na Educação um meio de mudança, que instiga nas pessoas, a criticidade, a solidariedade, e que estas, na sua diversidade, busquem ser participativas almejando mudanças e melhorias para a civilização como um todo. No espaço escolar os profissionais da Educação tem por finalidade formar alunos que possam se relacionar uns com os outros, e que estes na busca por conhecimentos, se tornem mais críticos, participativos que saibam agir na sociedade e no mundo em sua volta.

Entre os diversos profissionais da Educação, o professor tem um papel crucial nesses direcionamentos, visto que é o responsável direto pela formação dos seus alunos na instituição escolar. Assim, tem-se intensificado as pesquisas em torno da formação de professores na 


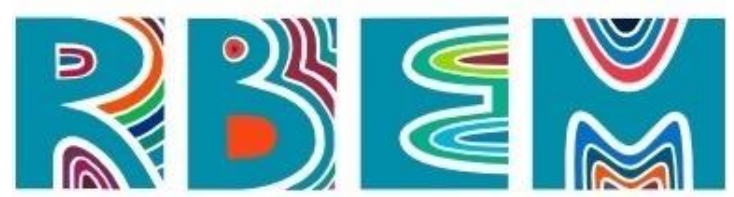

REVISTA BAIANA DE EDUCAÇÃO MATEMÁTICA

tentativa de alcançar uma escola almejada pela sociedade como um todo.

Segundo Mizukami (2002) a formação inicial pode ser compreendida pelo modelo da racionalidade técnica ou da racionalidade prática. O modelo de racionalidade técnica compreende que o professor é um técnico especialista que ensina por meio de teorias e técnicas. Logo, é na formação inicial que acontece a apropriação do conhecimento para ser aplicada futuramente na atuação profissional. Por outro lado, existe a necessidade de superar a "relação mecânica e linear entre o conhecimento científico e técnico e a prática concreta de sala de aula" (MIZUKUZAMI, 2002, p. 20), nessa vertente, entre as diversas abordagens de práticas reflexivas, existe um consenso de importância, que na formação inicial às práticas reflexivas se fazem presentes, no qual, o aluno possa realizar experiências, que mesmo cometendo erros, possa repensar sobre os seus atos e realizar novamente a sua prática de uma outra maneira.

Como professoras nos cursos de Licenciatura Plena em Matemática, compreendemos que, na formação inicial, o aluno deve ser instigado na qualidade de futuro professor, a prática reflexiva, ao estudo, a pesquisa, ao diálogo com seus pares, compreendendo que a graduação é apenas o início de um caminho. Coadunamos com o entendimento de Mizukami (2002) que, ao tornar-se um profissional da educação, a formação deve ser contínua.

Ademais, deve desencadear uma inquietação no que tange ao futuro da profissão de professor, que é muito além de um mero emprego, "Você pode ter um emprego como professor e exercê-lo bem, mas, se a escolha for de profissão, e não de mero emprego, o trabalho acadêmico vai, necessariamente, incluir a pesquisa, a investigação, a ousadia”. (FREITAS, 2002, p. 1).

Nessa vertente, enquanto pesquisadores da Educação Matemática, somos desafiados a todo momento a repensar a formação inicial. Entre as diversidades de pesquisas desenvolvidas em torno da formação de professores, nesse artigo nos atentaremos ao estudo e discussão da formação inicial, mais precisamente sobre o Estágio Supervisionado como componente curricular.

$\mathrm{Na}$ formação inicial, a disciplina de Estágio Supervisionado como componente curricular nos cursos de licenciatura possui uma carga horária de 400 (quatrocentas horas) que devem ser distribuídas no decorrer do curso, devendo contemplar a formação atuando diretamente na Educação Básica. O componente curricular de Estágio Supervisionado por 


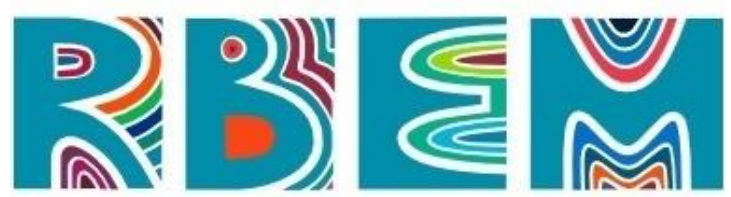

REVISTA BAIANA DE EDUCAÇÃO MATEMÁTICA

muito anos, e até mesmo nos dias atuais, vem se reproduzindo como uma disciplina de "prática", momento no qual o aluno após o estudo "teórico" terá oportunidade de colocar em prática tudo o que tem aprendido no decorrer do curso. Nessa perspectiva, estamos compreendendo que o Estágio Supervisionado está além da relação prática que historicamente vem apresentando, corroboramos com a compreensão de Pimenta:

Entendemos que o estágio se constitui como um campo de conhecimento, o que significa atribuir-lhe um estatuto epistemológico que supera sua tradicional redução à atividade prática instrumental. Enquanto campo de conhecimento, o estágio se produz na interação dos cursos de formação com o campo social no qual se desenvolvem as práticas educativas (PIMENTA, 2006, p. 6).

Nessa concepção, o componente curricular de Estágio Supervisionado representa um grande desafio para os pesquisadores na área da Educação Matemática, pois, implica em desenvolver espaços de estudos, nos quais todos os envolvidos tenham condições de participar efetivamente em um processo não verticalizado, com trocas de experiências e aprendizagens mútuas, tanto do formador quanto do professor em formação.

Desse modo, compreendemos que o componente curricular de Estágio Supervisionado não é o reducionismo entre atividade teórica e prática, mas sim

[...] o estágio, nessa perspectiva, ao contrário do que se propugnava, não é atividade prática, mas atividade teórica, instrumentalizadora da práxis docente, entendida esta como a atividade de transformação da realidade. Nesse sentido, o estágio atividade curricular é atividade teórica de conhecimento, fundamentação, diálogo e intervenção na realidade, este sim objeto da práxis. Ou seja, é no trabalho docente do contexto da sala de aula, da escola, do sistema de ensino e da sociedade que a práxis se dá. (PIMENTA, 2006, p. 6).

Nesse sentido, trabalhar com o componente curricular de Estágio Supervisionado de modo que seja uma reflexão sobre a prática e não meramente "prática" é a proposta dos formadores, diante dos desafios da formação inicial. Nesse contexto, estamos discutindo sobre o Estágio Supervisionado sendo desenvolvido diretamente no ambiente de trabalho do futuro professor: a escola. Entretanto, nos dias atuais diante do cenário pandêmico do COVID-19, os cursos de formação de professores presenciais tiveram que se adaptar as novas medidas de proteção contra o vírus. Com isso, esses cursos começaram a desenvolver as suas aulas completamente no modelo remoto, bem como, as escolas da Educação Básica. 


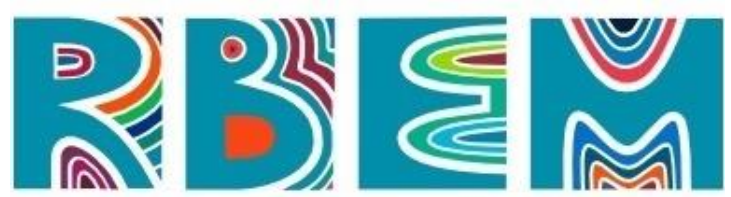

REVISTA BAIANA DE EDUCAÇÃO MATEMÁTICA

Diante dessa realidade, surgem alguns questionamentos: Como está sendo desenvolvido o componente curricular de Estágio Supervisionado? Em quais condições e restrições os futuros professores estão desenvolvendo o Estágio Supervisionado? Quais os desafios e possibilidades no desenvolvimento do Estágio Supervisionado no modelo remoto?

No decorrer deste artigo, pretendemos dialogar e refletir sobre essas indagações a partir das nossas experiências enquanto formadoras de professores que trabalham em cursos de Licenciatura Plena em Matemática. Bem como, por meio dos relatos de experiências de graduandos de uma instituição federal de ensino que vivenciaram o componente curricular do Estágio Supervisionado pelo ensino remoto.

Como integrantes do Grupo de Estudos em Didática da Matemática (DDMat) ${ }^{1}$, atentamos para a importância das pesquisas e dos estudos em torno do ambiente escolar, e temos visto o quanto o modelo teórico da Teoria Antropológica do Didático (TAD) permite investigar as relações pessoais e as relações institucionais, possibilitando um estudo das relações entre os objetos, sujeitos e instituições, resultando numa melhor compreenssão dos fenômenos didáticos. Certamente, essa tem sido uma teoria com uma visão ampla para pesquisar sobre formações de professores e todos os elementos que compõem o âmbito escolar, entendendo que além de possuir ferramentas para analisar o ensino de matemática, possui possibilidades de compreender o entorno da prática escolar, como a própria escola, a pedagogia e a sociedade.

Desse modo, nos apropriamos dessa teoria, mais precisamente dos níveis de coodeterminação para analisar e compreender o desenolvimento do componente curricular do Estágio Supervisionado, quando o Ministério da Educação (MEC) por meio da portaria 343, orienta que as aulas presenciais fossem substituídas por aulas em ambientes virtuais, no inicío da pandemia em 2020. Naquele exato momento, Universidades e Escolas da Educação Básica não tinham direcionamentos de como continuar ou proceder os estudos, até porque, não sabíamos se a pandemia terminaria em dias, semanas ou meses. Nesse cenário de incertezas, a vida escolar tinha que continuar independente das situações que foram surgindo, em particular a disciplina de Estágio Supervisionado II que investigamos e apresentamos neste texto.

Organizamos este artigo primeiramente apresentando nosso aporte teórico, a noção de níveis de coodeterminação da (TAD) que mobilizamos em nossas análises, em seguida a ${ }^{1}$ http://grupoddmat.pro.br/ 


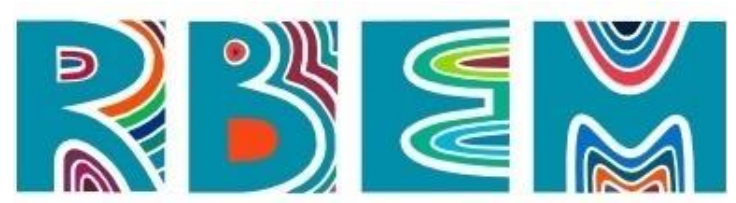

metodologia utilizada e a turma de estágio que desenvolvemos nossos estudos e análises e, ao final, tecemos nossas considerações.

\section{Níveis de coodeterminação}

Na pesquisa realizada por Santos e Freitas (2013), identificamos ao analisar a prática pedagógica in loco, que existe uma diversidade de fatores que não estão somente presentes na sala de aula, ou na escola, mas em um meio mais amplo, como na sociedade, e que interferem diretamente no contexto em sala de aula e, principalmente, na prática pedagógica. Nesse viés, a TAD, por meio dos níveis de coodeterminação, propicia entender esses fatores (sejam didáticos ou não) que perpassam o âmbito escolar.

As concepções de praxeologia na TAD permitem afirmar que "[...] a didática se dedica a estudar as condições e restrições sob as quais as praxeologias começam a viver, migrar, mudar, operar, perecer, desaparecer, renascer, etc. dentro dos grupos humanos, isto é, nas instituições sociais." (CHEVALLARD, 2007, p. 14). Para estabelecer uma praxeologia relacionada com o saber matemático, esse saber deve estar associado a uma escala hierárquica, na qual cada nível corresponde a uma realidade e determina os hábitats ${ }^{2}$ e nichos ${ }^{3}$ das OM e OD, conforme aponta Chevallard, na Figura1.

\footnotetext{
${ }^{2}$ Para Chevallard (1994): O hábitat de um objeto matemático refere-se à instituição na qual se encontra o saber, o lugar seu endereço.

${ }^{3} \mathrm{O}$ nicho corresponde à relação do saber com o objeto de estudo, determinando a função do saber, ou seja, seu nicho. (CHEVALLARD, 1994).
} 


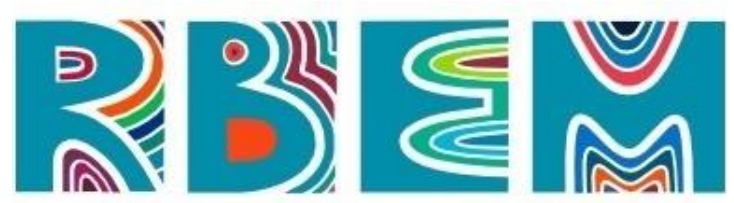

\section{Civilização

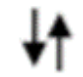 \\ Sociedade \\ $\downarrow \uparrow$ \\ Escola \\ $\downarrow \uparrow$ \\ Pedagogia \\ $1 \mathbf{1}$ \\ Disciplina \\ $\downarrow \uparrow$}

Dominio

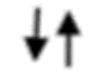

Setor

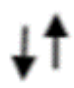

Tema

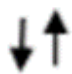

Assunto

Figura 1 - Níveis de Coodeterminação Chevallard (2009a, p. 12).

Para Chevallard (2009b, p. 1): "a didática é a ciência das condições e restrições de difusão social das praxeologias", ou seja, a didática é a ciência do estudo, na qual uma pessoa ou uma instituição quer fazer algo para que a outra pessoa ou instituição aprenda sobre algo. Certamente, é importante entender a singularidade das palavras "condições" e "restrições". Conforme Chevallard, "no princípio tudo é condição" (2009a, p. 12). Uma condição passa a ser restrição para uma instituição ou pessoa, no momento em que essa condição não pode ser modificada pela instituição ou pessoa, entretanto, as condições não são restrições quando são modificáveis. (CHEVALLARD, 2009a). 


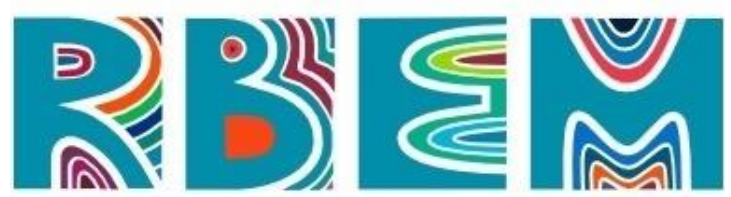

REVISTA BAIANA DE EDUCAÇÃO MATEMÁTICA

Assim, as condições e restrições que são os seus objetos de estudos, e que não podem ser enumeradas a priori, bem como a compreensão de seu papel na difusão de uma determinada entidade praxeológica ${ }^{4} \wp$, são os objetivos das pesquisas em didática. Cada nível dessa escala é fonte de algumas condições que são como restrições em outros níveis, são possíveis de serem questionadas ou analisadas, mas não modificadas.

Ao definir didática, Chevallard (2007) primeiramente afirma que, para que exista didática - e não apenas aprendizagem - deve existir alguma intenção didática, e que o portador dessa intenção didática seja uma pessoa ou instituição que procura modificar ou criar condições e restrições para alcançar a intenção, mas que pode necessariamente não alcançar. No entanto, nessa perspectiva, não é possível ficar limitado somente às condições e restrições que surgem em uma determinada intenção didática:

Para estudar, por exemplo, a eficácia de tal sistema de condições e restrições - isto é, de tal organização didática - criada em uma classe por um professor, pode-se ter que levar em conta as condições e restrições que não foram criadas pelo professor, e que não respondem a nenhuma intenção didática claramente identificável. (CHEVALLARD, 2007, p. 16, tradução nossa).

Neste sentido, vale salientar, segundo Chevallard (2007), que ao observar o efeito de condições e restrições sobre os mecanismos de difusão das praxeologias, podemos nos deixar levar por considerar que tais condições e restrições são exteriores ao campo de estudo do didático, e que o professor deve interessar-se somente pelas condições e restrições que supõe fazerem parte da classe escolar. Conforme o autor, o papel do professor vem sendo historicamente construído nessa perspectiva e ele questiona: "quando um professor de matemática encontra (oficialmente) os pais de um aluno, o didático está em jogo?" (CHEVALLARD, 2007, p. 16).

Para Chevallard (2007), os pais são evidentemente portadores de condições e restrições, nas quais alguns procedem explicitamente a sua intenção didática em "fazer qualquer coisa" para o êxito escolar do seu filho. Certamente, o professor a partir de uma intenção didática pode mudar e confrontar algumas condições e restrições, criar novas intenções didáticas entrando no campo da investigação do didático e saindo das fronteiras tradicionais de ensinar. Por outro lado, o professor não deve ignorar que o próprio aluno é

${ }^{4}$ As entidades praxeológicas cuja notação genérica $\wp$ são um tipo de obra, que admitem casos especiais como saber e saber-fazer da cultura comum. (CHEVALLARD, 2009a). 


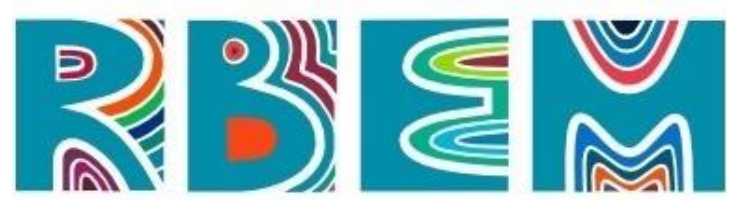

REVISTA BAIANA DE EDUCAÇÃO MATEMÁTICA

portador de um heterogêneo campo de condições e restrições sensíveis ao conteúdo estudado. Assim sendo, o professor não deve atribuir aos seus alunos estudos independentes dos conteúdos, ou seja, sem considerar a realidade que vivencia seu aluno.

Podemos compreender os níveis de coodeterminação subdivididos em dois subníveis, conforme Chevallard (2002): níveis superiores (Civilização, Sociedade, Escola e Pedagogia) e níveis inferiores (Disciplina, Domínio, Setor, Tema e Objeto), neste artigo, as nossas análises serão norteadas somente pelos níveis superiores. Na escala, a seta dupla representa que a criação ou modificação de uma condição em um determinado nível pode fazer a diferença nos demais níveis. Para os níveis superiores, temos na Figura 2 a seguinte escala:

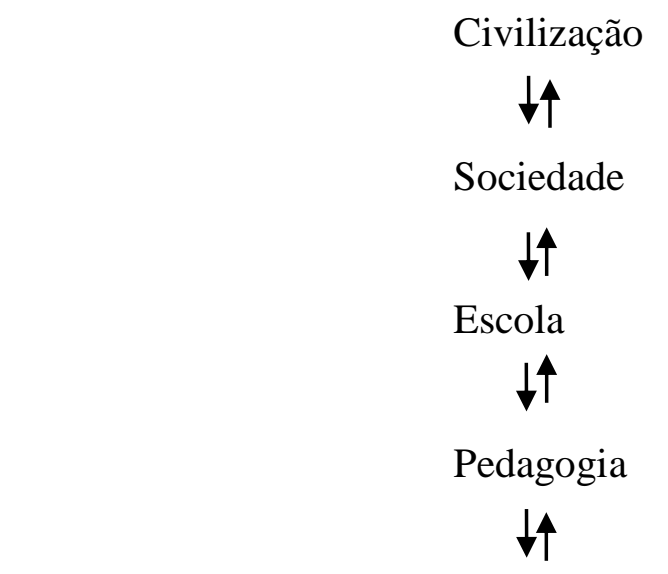

Figura 2- Níveis superiores de coodeterminação Chevallard (2009a, p. 12).

Os níveis superiores correspondem às condições e restrições impostas por situações para além da sala de aula, que não foram criadas pelo professor, mas afetam diretamente na execução das suas praxeologias. Nesse cenário, podemos exemplificar diferentes situações, entre elas, o cenário pandêmico atual, COVID-19, que fez com que todos os envolvidos no ambiente escolar mudassem suas práticas por medidas de segurança.

Assim, podemos observar que no ambiente escolar existem diferentes situações correlacionadas aos níveis superiores que implicam diretamente a prática do professor em sala de aula, cabendo aos pesquisadores em didática compreender que são situações que precisam ser analisadas mesmo que não possam ser modificadas, como afirma Chevallard (2009a):

[...] Cabe aos pesquisadores didáticos levar em conta tanto quanto é possível em um determinado momento todas as condições que eles suspeitam que pesam na difusão praxeológica estudada, embora não tenham capacidade 


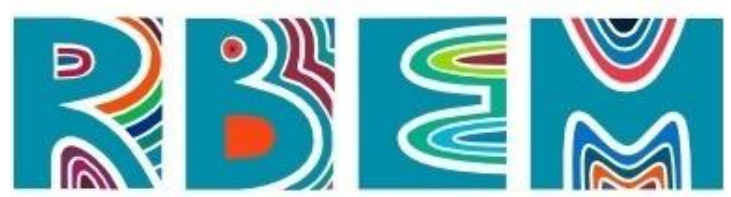

REVISTA BAIANA DE EDUCAÇÃO MATEMÁTICA

para ter essas condições modificadas de uma maneira eventualmente desejada. (CHEVALLARD, 2009a, p. 13, tradução nossa).

Desse modo, os níveis de coodeterminação representam, em cada nível, os assujeitamentos de $\mathrm{X}$ em relação às Instituições $\mathrm{I}_{\mathrm{i}}$. Nos apropriamos dos níveis de coodeterminação, e dos níveis superiores para compreender quais as condições e restrições impostas aos estudantes universitários para o desenvolvimento do componente curricular do Estágio Supervisionado durante o início da pandemia em Março de 2020. Período no qual universidades e escolas da Educação Básica não sabiam como proceder inicialmente com as atividades escolares, visto que desconheciam sobre a propagação do vírus que resultou na modalidade do ensino remoto, e que a priori poderia ser atividades de dias ou meses, porém, naquele momento não imaginaríamos que seria uma situação vivenciada por anos. $\mathrm{Na}$ sequência apresentaremos uma breve contextualização da disciplina e da turma.

\section{O componente curricular do Estágio Supervisionado II}

O Projeto Pedagógico do Curso (PPC) de Matemática - Licenciatura de Campo

Grande da Universidade Federal de Mato Grosso do Sul (UFMS) prevê 102 horas para a disciplina de Estágio Supervisionado II, sendo que sua ementa é composta pelas seguintes D) BE REISTA

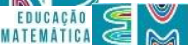
atividades:

Observação e análise do cotidiano escolar da escola de Ensino Fundamental. Análise de livros didáticos de matemática. Observação e análise de aulas de matemática nos anos finais do Ensino Fundamental (preferencialmente $8^{\circ} \mathrm{e}$ $9^{\circ}$ anos). Participação na regência de aulas de matemática nos anos finais do Ensino Fundamental. Planejamento, desenvolvimento e avaliação de aulas de matemática nos anos finais do Ensino Fundamental. Regência de aulas de matemática para alunos dos anos finais do Ensino Fundamental. Discussão de temas envolvendo relações de gênero, cidadania, direitos humanos e educação ambiental. (UFMS, 2019, p. 34).

Como vemos, boa parte das atividades do estágio são para serem realizadas no ambiente escolar. Todavia, em função da pandemia foi preciso repensar essas atividades, afinal não tínhamos como prever quando as atividades presenciais nas escolas iriam retornar. É importante frisarmos que naquele momento as escolas estavam também lidando com essa nova situação e que o ensino remoto emergencial estava em início de implementação, ou seja, não tínhamos direcionamentos de como desenvolver a disciplina de Estágio Supervisionado 


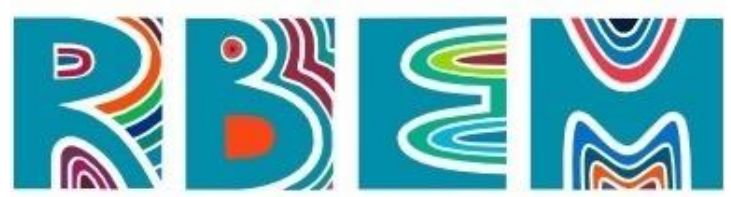

REVISTA BAIANA DE EDUCAÇÃO MATEMÁTICA

no Modelo Remoto. No entanto, era preciso continuar com as atividades das disciplinas do Curso de Matemática - Licenciatura, mas como dar prosseguimento no trabalho com as disciplinas de estágio? Diante dessa problemática, a direção do INMA juntamente com o Colegiado de Curso, em conformidade com a resolução no 228 de 13 de agosto de 2020, decidiram pela substituição total das atividades dos estágios, por atividades remotas com os professores orientadores dos estágios.

Em nossa pesquisa analisamos a produção de 14 acadêmicos da disciplina de Estágio Supervisionado II ministrada no segundo semestre de 2020, desenvolvida por meio de aulas síncronas e assíncronas, durante quintas feiras, no período matutino e também durante algumas segundas e terças feiras à tarde, conforme disponibilidade da turma. No caso, a produção de dados foram a partir dos relatórios finais dos estagiários entregues para aprovação dessa disciplina. Desse modo, nossa investigação se deu no estudo das condições que se impuseram para que esta disciplina ocorresse, mesmo diante das restrições imposta pela situação da pandemia. Assim, apresentaremos no próximo tópico contribuições e limitações do desenvolvimento do Estágio Supervisionado no modelo remoto.

\section{Análise das condições e restrições no desenvolvimento da disciplina}

Diante do cenário pandêmico, uma restrição imposta ao desenvolvimento do curso de matemática, totalmente presencial, foi a de tornar todas as suas atividades em não presenciais. Essa restrição evidenciou a necessidade da utilização de recursos tecnológicos na educação. Na sociedade é evidente o uso massivo dos recursos tecnológicos (celulares, tablets, internet), já na educação a utilização desses recursos também se fazia presente, no entanto, somente durante a pandemia fica explícito o quanto a utilização desses recursos na Educação por parte dos professores ainda são desafiadores, bem como, a escassez desses recursos por parte dos alunos. A desigualdade de acesso e as condições aos meios digitais são problemas recorrentes da pandemia, além de se tratar de um curso totalmente presencial, no qual os seus acadêmicos não tinham a necessidade desses recursos para conseguir cursar as disciplinas.

Com os desafios expostos ao professor perante a pandemia, como ter que vivenciar direcionamentos até então desconhecidos como a modalidade de Ensino Remoto, se intensificou a responsabilidade na busca por alguns recursos tecnológicos para serem utilizados durante as aulas. No caso do ensino da Matemática especificamente, os professores 


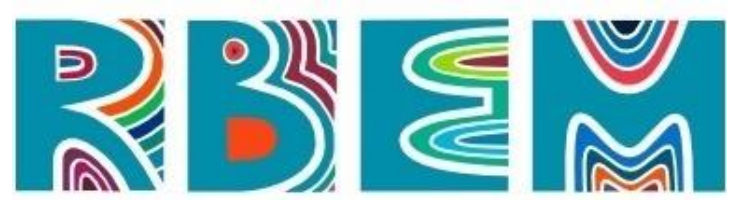

REVISTA BAIANA dE EDUCAÇÃO MATEMÁTICA

se depararam com situações em como ensinar as operações matemáticas sem uma lousa, ou como filmar e ao mesmo tempo fornecer a explicação do conteúdo, tendo que buscar aplicativos para facilitar as aulas síncronas.

Para o desenvolvimento do componente curricular do Estágio Supervisionado II, buscamos trabalhar com o Ambiente Virtual de Aprendizagem (AVA). As atividades foram desenvolvidas na plataforma do Moodle que é um ambiente:

[...] criado para auxiliar os educadores na elaboração de um espaço eficiente para aprendizagem. É um programa aberto que pode ser alterado pela comunidade científica, com objetivo de torná-lo pedagogicamente mais adequado. Nele, encontramos diversas ferramentas que permitem organizar um curso conforme modelo pedagógico escolhido. (BURIGATO; MOGELLI, 2018, p. 257).

Esse recurso foi importante para o desenvolvimento da disciplina, pois as atividades do estágio seriam realizadas tanto de modo síncrono como assíncrono, e esses acadêmicos não estavam acostumados com esse modo de ensino. Diante disso, a condição de escolha desse ambiente se deu pelo fato de ser um recurso de fácil manuseio pelos alunos e que permitia a interação entre os alunos e a professora da disciplina, como podemos observar a interface a seguir na Figura 3:

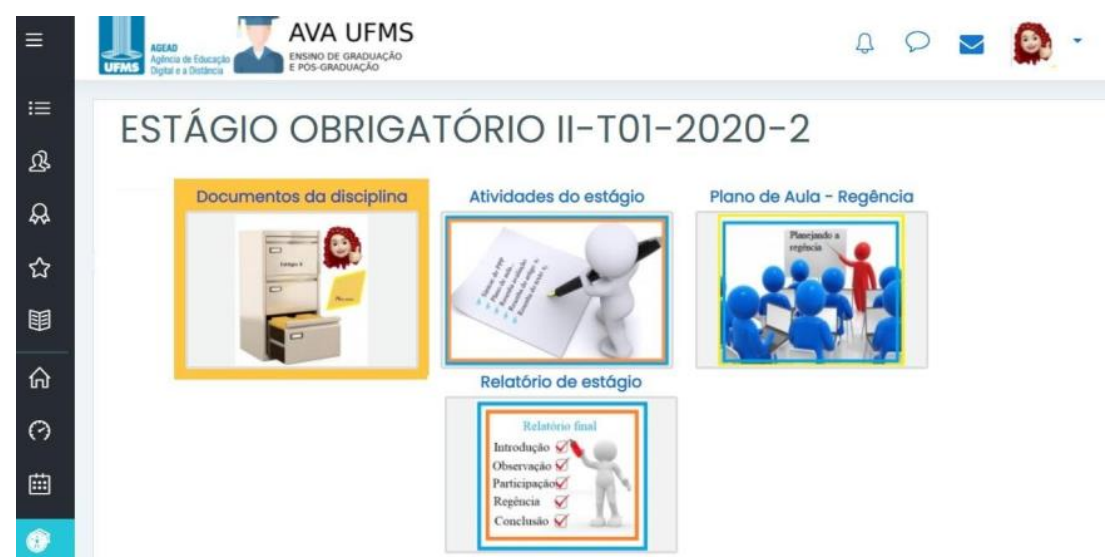

Figura 3 - Imagem do moodle da disciplina

$\mathrm{E}$, diante da restrição em desenvolver a disciplina totalmente remota, vale ressaltar que os encaminhamentos metodológicos (via Moodle) se deve pelo fato da Professora orientadora da disciplina de Estágio Supervisionado II ter experiência de nove anos em cursos na modalidade de Educação à Distância (EAD), utilizando esse ambiente. Assim, a criação e o 


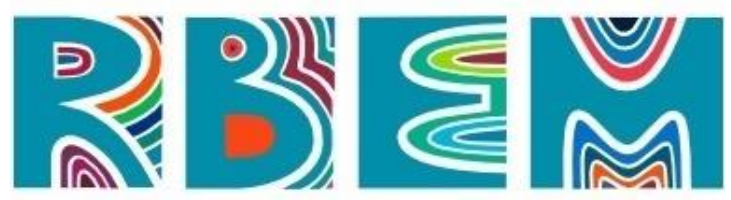

REVISTA BAIANA DE EDUCAÇÃO MATEMÁTICA

desenvolvimento das aulas nesse espaço não resultou em grandes desafios, pois ela já tinha contato e experiência com aulas on-line. $\mathrm{O}$ que, de certo modo, contribuiu para que essa docente buscasse outras possibilidades para promover a interação entre os acadêmicos diante da realidade em que o estágio iria acontecer.

É importante destacar que os acadêmicos do curso de Matemática - Licenciatura da UFMS foram submetidos a aceitar as condições impostas pela Instituição, visto que a não participação na disciplina ocasionaria na reprovação do componente, independentemente se esse acadêmico possuía ou não acesso à internet ${ }^{5}$, computador ou celular para realizar as suas aulas.

Assim, o componente curricular do Estágio Supervisionado, totalmente no modelo remoto e com a carga horária de 102 horas, foi distribuído entre as seguintes atividades desenvolvidas somente no AVA da Universidade: análise do PPP (Projeto Político da Escola) - os alunos analisaram o PPP das escolas; análise do livro didático - os alunos analisaram diferentes conteúdos propostos nos livros didáticos e as regências - os alunos ministraram aula via meet para os colegas da turma simulando hipoteticamente uma situação real de sala de aula.

Uma condição inicial para os encaminhamentos da disciplina foi de buscar situações de modo que mesmo o aluno não tendo a oportunidade de estar presencialmente na escola, este pudesse de alguma forma conhecer e entender o seu funcionamento. Para tanto, foi acordado aos acadêmicos que analisassem o PPP da escola que iriam estagiar presencialmente, visto que já tinham tido o contato inicial com a escola para iniciar as atividades de observação. Nessa proposta inicial de encaminhamento da disciplina, os acadêmicos pontuam que

[V.H.] - [...] outra tema que nos enriqueceu como professores em formação foi o Projeto Político Pedagógico (PPP) sendo ele a base para toda escola funcionar, onde é colocado sua missão, visão e valores, servindo de norte para o processo de ensino da escola, todos os pais deveriam entender sobre o PPP pois mostra todo o caminho que a escola irá traçar. (V. H., 2020).

[...] Foi uma experiência muito interessante a elaboração desta atividade, ela foi realizada em grupo, no ambiente de aprendizagem virtual da UFMS, o AVA. [...] ressaltou a importância de conhecer e se aprofundar em questões

\footnotetext{
${ }^{5}$ É importante salientar que a UFMS abril edital para empréstimo de equipamentos tecnológicos e também para pacotes de internet para os alunos que não tinham. Todavia quando esta disciplina que estamos analisando aconteceu, ainda tínhamos muitos alunos que não haviam sido contemplados com esses editais.
} 


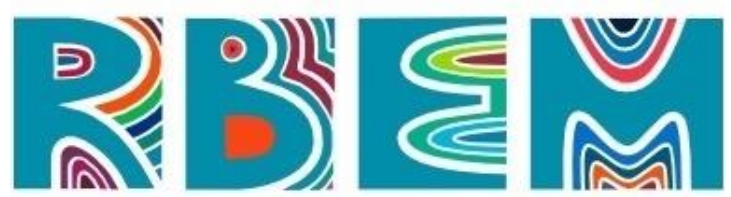

REVISTA BAIANA DE EDUCAÇÃO MATEMÁTICA

de documentos, leis, diretrizes, pois são elas que norteiam os rumos da educação e ainda futuramente poderíamos ser convidados a elaborar textos semelhantes. Na prática da atividade, não imaginava que todas as escolas precisavam ter um documento tão rico de detalhes como este. Já havia estudado como empresas possuem missão, visão e valores como parte de sua gestão organizacional, mas não sabia que cada escola também possuía estes três itens e que os mesmos podem ser encontrados no PPP de cada uma. (L.S., 2020).

Como vimos nos relatos dos acadêmicos, estes puderam entender e compreender o quanto o PPP da escola é um documento norteador para a atuação de todos os envolvidos no ambiente escolar, inclusive para o professor. Nessa proposta, além de terem essa compreensão, a atividade proporcionou aos acadêmicos conhecerem algumas ferramentas do Moodle, como o Wiki, onde os acadêmicos distribuídos em grupos (que presencialmente acompanhariam as atividades de uma mesma escola) estudassem e desenvolvessem um texto em conjunto com os colegas sobre o PPP. Tal recurso foi interessante conhecer e manusear, visto que esses acadêmicos não o conheciam, e que foi uma condição importante para o desenvolvimento de um trabalho em grupo no ensino remoto.

Desse modo, diante das restrições impostas, as atividades da ementa da disciplina foram adaptadas para o ensino via remoto buscando proporcionar momentos de trocas de experiências entre os acadêmicos, principalmente com relação as atividades de observação, participação e regência. Como dito anteriormente, no cenário inicial da pandemia a disciplina que estava inicialmente prevista para acontecer em uma escola específica, e que alguns acadêmicos já haviam iniciado o contato para estagiar, foram realizadas somente na UFMS. Essa escolha se deu pelo fato de que, naquele exato momento, as escolas ainda estavam começando a se organizar em como proceder com as suas atividades escolares via remota. Os professores ainda estavam começando a trabalhar nas salas de aula via Google e no desenvolvimento das Atividades Pedagógicas Complementares (APCs).

Nesse contexto, na continuidade da disciplina, propusemos aos acadêmicos a análise de livros didáticos de $8^{\circ}$ e $9^{\circ}$ ano, os utilizados nas escolas que tiveram contato inicial para estagiar. Compreendemos que o livro didático é um recurso muito utilizado pelos professores, ou algumas vezes o único utilizado, assim é de suma importância que desde a formação inicial os acadêmicos façam uma leitura crítica sobre este recurso, diante dessa atividade o acadêmico M. P. L., pontua: 


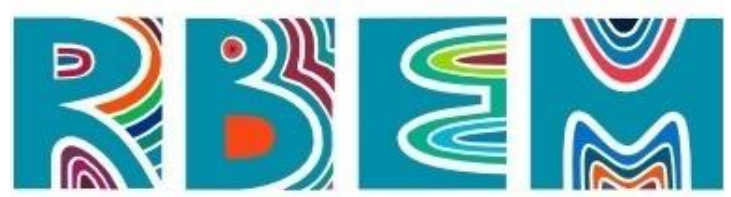

REVISTA BAIANA DE EDUCAÇÃO MATEMÁTICA

A partir desta análise, é possível ressaltar a importância de o professor ser crítico em relação ao livro didático. Este recurso deve ser usado como ferramenta de ensino, com uma utilização adequada, buscando complementar o que este material oferece. Outro ponto importante que vale destacar e que no decorrer da disciplina de Estágio Supervisionado II, foi possível perceber que a maioria dos professores não faz uso do manual destinado a ele no livro didático, embora utilizem alguns recursos e orientações didáticas para abordar conteúdos matemáticos, diferente da maneira sugerida pelos autores. (M.P.L., 2020).

Ao apresentar a análise dos livros didáticos, verificamos uma condição imposta aos acadêmicos com relação a esse recurso, pois, para eles as definições presentes nos livros didáticos estão sempre corretas, não sendo necessário questionar a sua veracidade, nessa opinião, vemos que o objeto matemático no livro didático possui uma relação não modificável que o professor pode ensinar apoiado no livro, sem qualquer questionamento dos conceitos apresentados. Todavia, essas discussões foram sendo ampliadas com as análises dos livros com as discussões propostas pelo Programa Nacional do Livro Didático (PNLD). Desse modo, no decorrer da atividade essa concepção foi modificada, visto que analisaram se os livros possuíam erros conceituais e, além disso, pontuaram que os livros apresentam em sua maioria apostilas de exercícios superficiais como menciona G.F.O.J:

Os conteúdos abordados não possuem erros conceituais, mas são trazidos sem grandes contextualizações, não há também nos capítulos estudados aspectos relacionados a matemática crítica nem a modelagem matemática. Os exercícios presentes nos capítulos são majoritariamente exercícios de execução dos conceitos abordados anteriormente, não há também exercícios voltados para a investigação matemática. E há poucos exercícios que incentivam a interação entre os alunos. (G.F.O.J., 2020)

Certamente, podemos inferir que os acadêmicos se sujeitassem às condições impostas pelo livro didático, e que no decorrer das discussões propostas na disciplina, com estudo de outros textos de pesquisas e também com o PNLD, conforme relato de G.F.O.J., vão modificando suas afirmações com relação ao uso do livro didático. Evidenciando assim, a importância de buscar livros didáticos que possibilitam um trabalho mais contextualizado, que explore diferentes situações, problemas, entre outras possibilidades.

Na disciplina, os acadêmicos se depararam com uma segunda restrição no decorrer do estágio: eles não teriam contato com os professores atuantes na Educação Básica e nem havia 


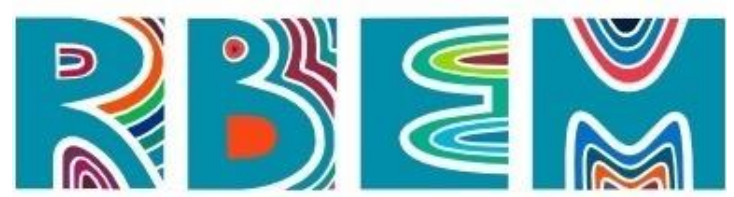

REVISTA BAIANA DE EDUCAÇÃO MATEMÁTICA

a possibilidade de interação com estudantes das escolas, ou com os níveis de ensino que seriam trabalhados no Estágio Supervisionado II. Com isso foi necessário repensar a organização das ações que seriam realizadas nas instituições, considerando que as atividades seriam realizadas somente com a participação da Professora orientadora do estágio e com os acadêmicos.

Assim, foi proposto uma dinâmica de simulação de uma sala de aula. Buscando com isso contemplar os momentos de observação, participação e regência previstos na ementa do estágio, mas considerando a especificidade daquele momento, ou seja, essas atividades seriam realizadas somente com a turma do estágio. Desse modo, os momentos de regências foram realizados de modo síncrono via Google Meet com todos os acadêmicos da disciplina participando como se fossem alunos do $8^{\circ}$ ou $9^{\circ}$ anos, conforme o ano de regência do momento. A ideia era proporcionar ao acadêmico uma experiência tanto com relação ao tempo necessário para ministrar a aula preparada, como também de prepará-lo para responder possíveis questões e/ou dúvidas que um aluno daquele nível poderia ter com a aula que ele havia planejado e que estava apresentando. Foi sugerido que eles usassem algum recurso didático na sua aula como, por exemplo, jogos, software, materiais manipuláveis, etc. Buscando meios que favorecessem tanto a construção de um conceito matemático, objetivo de ensino da aula, como também os momentos de interação entre os participantes durante a aula via Google Meet.

Assim, foi acordado que as questões e dúvidas que seriam suscitadas pelos colegas da turma, para o acadêmico que estava ministrando a regência, deveriam condizer com o que um aluno, por exemplo, do $8^{\circ}$ ano faria ao professor em sala de aula. Tais condições para o desenvolvimento da disciplina permitiram que os alunos vivenciassem momentos de estudo, favorecendo discussões sobre possíveis situações do ambiente escolar, que contribuíram para a sua formação, como pontuam alguns acadêmicos:

[...] Este Estágio foi anômalo em relação aos outros pois estamos enfrentando uma pandemia mundial. Acredito que esta foi uma oportunidade única de vivenciarmos a educação de uma maneira nunca vista ou vivida, e estar nesta posição neste momento nos mostrou as possíveis dificuldades que professores enfrentam. (N.O. S., 2020)

[...] A disciplina de estágio nos proporcionou uma oportunidade ímpar, pois nos levou para a sala de aula de forma ilustrativa, tive a oportunidade em outra disciplina de estágio de fazer vídeo aulas, contudo nesta foi algo 


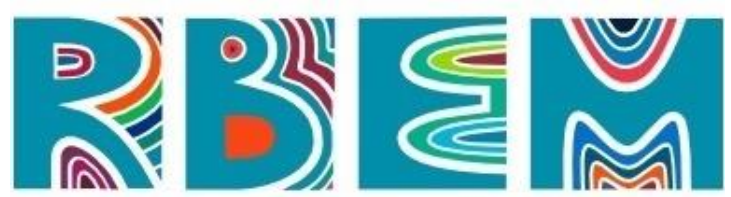

REVISTA BAIANA DE EDUCAÇÃO MATEMÁTICA

diferente pois demos aula em lives com a interação de nossos colegas, assim ilustrando uma sala de aula. O COVID 19 nos trouxe vários problemas, todavia conseguimos resolve-los quase todos, um deles foi o fato da aula ser remota, porém aprendemos muito sobre a tecnologia fora e dentro de sala de aula, quando realizamos a aula achei algo muito forçado pois gosto muito da relação professor e aluno, entretanto após os colegas realizarem suas aulas, levantamos várias situações que poderíamos enfrentar em sala de aula, com isso tornou a disciplina de estágio algo muito enriquecedor e farto de conhecimento e experiências. (V. H., 2020).

[...] Foi feita a observação da regência da professora estagiária [...]. Ela usou slides como recurso para ministrar a aula. Respondeu com atenção e cuidado às perguntas que foram feitas pelos alunos. Formou duplas ou grupos e propôs 6 desafios para cada um fazer. Corrigiu os desafios com a turma. Foi uma das aulas em que os alunos mais interagiram, tanto positivamente, comentando na aula, fazendo perguntas tanto negativamente com conversas paralelas no chat e até áudio ligado. Foi uma experiência interessante, porque ficou muito próximo da realidade de uma sala de aula e ela soube lidar muito bem com toda essa situação. (L.S., 2020)

[...] um problema encontrado, [...], foi o tempo de hora/aula utilizado em seu plano, incompatibilizado com sua apresentação. Creio que detalhes como este, só se corrige com o tempo e com a prática docente. A professora em sala comentou que o tempo de hora/aula é importante estar adequado com a aula ministrada, para que não nos percamos dentro do cronograma da escola. (M.P.L., 2020)

$\mathrm{Na}$ fala dos acadêmicos L.S e V.H vemos que a proposta de simularmos uma sala de aula, apesar de ter sido vista inicialmente como uma situação forçada por um deles, acabou se mostrando como pertinente ao momento vivenciado. Possibilitando momentos de discussão e reflexão sobre as atividades que estavam sendo implementadas; como do tempo necessário para apresentação de uma aula planejada; em como conduzir uma atividade aplicada remotamente, quais possíveis interações que este ambiente pode proporcionar; quais recursos tecnológicos utilizar para o ensino em uma aula remota, entre outros. São aspectos importantes para o futuro professor de matemática e que só foram possíveis pela situação vivenciada pelo ensino remoto, como pudemos identificar nas falas de alguns acadêmicos, e que a seguir trazemos um exemplo:

[...] O desenvolvimento de um plano de aulas remotas é o momento ideal para colocarmos em prática novas ideias e fomentar as aprendizagens ativas. Ressaltamos que o ensino a distância é benéfico, e, com criatividade, podemos enxergar grandes oportunidades, principalmente em momentos de desafios. Também discutimos sobre o tempo de tais aulas, que não devem ser muito extensas a ponto de dispersar a atenção dos alunos. (D., 2020). 


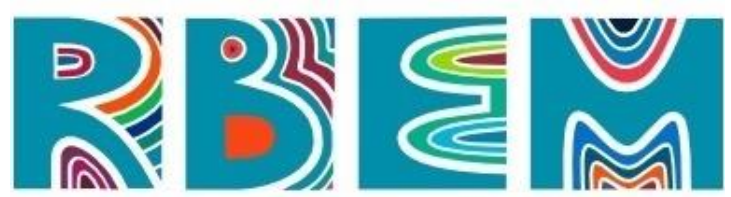

REVISTA BAIANA DE EDUCAÇÃO MATEMÁTICA

É um fator importante a se considerar, essa experiência já na formação inicial de um licenciando, pois, um fato que vem sendo discutido nesse momento de pandemia é sobre como será o ensino após esse período. Alguns argumentam que muitos desses recursos implementados, como encontros via Google Meet (ou outros), discussões via WhatsApp, disponibilização de vídeos para os alunos, dentre outros, serão agregados ao ensino presencial, como um recurso a mais para professores e estudantes de todos os níveis escolares. Também concordamos com isso, e certamente foi a difícil situação imposta pela pandemia que deu condições para que esses acadêmicos vivenciassem essa experiência já na sua formação inicial.

[...] não foi fácil e posso considerar um desafio gigantesco ser pioneiro em tempos de pandemia. Posso dizer que em anos de existência, os estágios nunca foram realizados como os que estão sendo no ano de 2020. [...] Considero também um passo importantíssimo para a produção de novos conteúdos utilizando novas ferramentas. Por meio das atividades realizadas, foi possível afirmar que o Estágio Supervisionado é considerado por nós, acadêmicos, como espaço de produção da aprendizagem envolvendo estudo, reflexão e proposição de soluções às situações de ensinar e de aprender. (D.R.R, 2020).

[...] A produção de conhecimento por meio do uso das mídias e de seus recursos tecnológicos se faz necessária e deve ser promovida pelos martenafich educadores nos cursos de formação inicial e de formação continuada. Entende-se que seu uso tem potencial de dinamizar o conhecimento e proporcionar maior eficiência às práticas pedagógicas, considerando o seu poder de interação, o qual contribui para superar os desafios enfrentados pela educação, sobretudo em tempo de pandemia. (E.D.E., 2020).

$\mathrm{Na}$ fala final desse acadêmico vemos que o estágio cumpriu seu papel como uma atividade teórica e instrumentalizadora da práxis docente (PIMENTA, 2006). Ao se constituir como um espaço de estudos teóricos e de implementação de atividades, oportunizado pelos momentos de diálogos e de reflexão. Possibilitando assim, pensar em meios para se transformar a realidade imposta, mesmo em um momento tão adverso como o imposto pela pandemia.

Os momentos de observação de aula previstos foram contemplados com esses momentos de regência simulada. $\mathrm{O}$ acadêmico deveria escolher duas regências, uma do $8^{\circ} \mathrm{e}$ outra do $9^{\circ}$ ano, para fazer o seu relatório de observação. Para contemplar o momento de participação, o estudante deveria auxiliar um colega na elaboração de uma aula com uso de algum recurso e de um tutorial de como utilizar o recurso em sala de aula. Cada acadêmico 


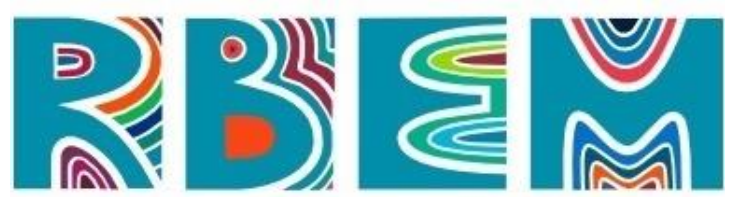

REVISTA BAIANA DE EDUCAÇÃO MATEMÁTICA

ministrou duas regências, uma que ele planejou sozinho e outra que ele planejou com auxílio de um colega. Na Figura 4, a seguir, podemos observar no plano dessa disciplina como foram distribuídas as 102 horas do estágio. Tanto esses momentos citados, envolvendo a regência, bem como as outras atividades previstas na ementa da disciplina.

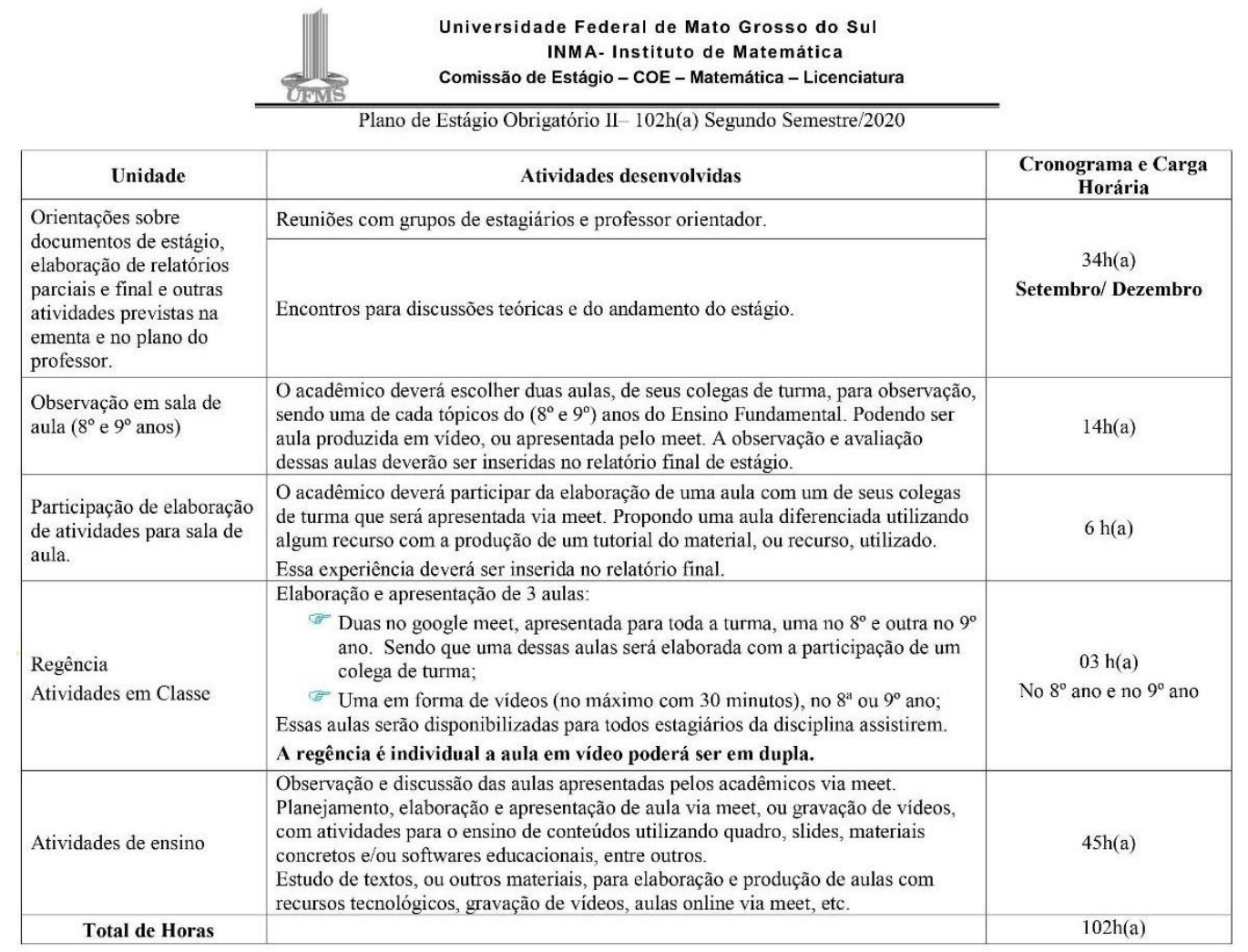

Figura 4 - Distribuição das horas da disciplina de Estágio.

Um aspecto que se tornou importante na interação do acadêmico, no momento de sua regência com a participação de seus colegas de turma, foi a proposta de simulação de uma sala de aula. A regência deveria seguir a programação de tempo normal de uma aula, e os participantes deveriam se comportar como alunos do respectivo nível da aula que estava sendo ministrada. Assim, deveriam observar se a apresentação estava clara, se os exemplos apresentados condiziam com o que estava sendo proposto pelo regente, fazer questões que jugassem pertinentes para um aluno daquele nível de ensino. Por exemplo, um estudante do $8^{\mathrm{a}}$ ano que tivesse assistindo a aula conseguiria realizar as atividades que eram propostas, no tempo que o regente estipulava para cada atividade? A linguagem utilizada, bem como as 


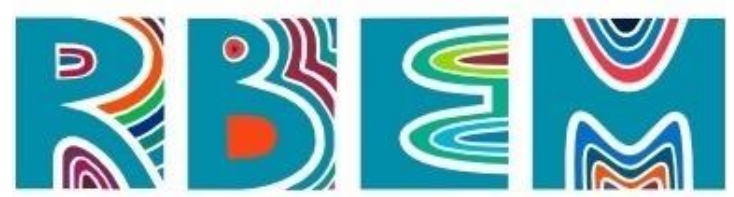

REVISTA BAIANA DE EDUCAÇÃO MATEMÁTICA

representações escritas, era adequada? Vejamos o relato de alguns acadêmicos sobre esses momentos:

[...] - Outro movimento inesperadamente rico em aprendizagem foi a iniciativa dos alunos da graduação de se comportarem como alunos do ensino fundamental durante a regência dos colegas, pois, mais uma vez ao fazer isso, somos forçados a mudar nosso ponto de vista e desta forma percebemos outros aspectos envolvidos nesta relação de aluno e professor. Assistindo a regência do colega $D$. foi especialmente intrigante para mim pois a inclusão de jogos na matemática de forma incorporada ao conteúdo já foi muito discutida durante a minha graduação, porém nunca tinha visto um exemplo tão bem aplicado quanto o do colega, acredito que esta experiência me proporcionou uma apreciação muito maior por jogos matemáticos ou mesmo jogos enquanto possíveis meios de aprendizagem. (N.O. S., 2020).

Nessa fala vemos que mesmo com a restrição imposta, no caso a falta de interação com alunos do ensino fundamental, os acadêmicos conseguiram vivenciar a implementação de outros recursos em suas regências. Eles participaram do jogo utilizado pelo colega regente e conseguiram refletir sobre o uso desse recurso visando a aprendizagem de um conteúdo matemático.

Outro aspecto importante oportunizado pela sala de aula simulada, foi a possibilidade de aprofundamento nos conceitos matemáticos que estavam sendo ministrado. Observamos que os acadêmicos ao interagirem com o colega que estava regendo a aula faziam questões sobre dúvidas que eles tinham sobre algum aspecto que estava sendo apresentado.

Outra mudança no planejamento do estágio foi a proposta de elaboração de um vídeo. Nesse momento de pandemia vimos como os professores das escolas precisaram se adaptar para o ensino remoto, e uma das estratégias que eles tiveram de implementar para suas aulas foi a elaboração de vídeos. Tanto envolvendo a apresentação de alguns conceitos matemáticos, como também com resoluções de atividades. Desse modo, acrescentamos a elaboração de um vídeo apresentando um conteúdo, ou resolvendo alguma atividade. Foi uma atividade para ser realizada em dupla, a ideia era que eles procurassem algum recurso para tornar mais interessante o vídeo, de modo que não fosse a simples leitura de alguns slides. Mas que eles conseguissem, por exemplo, resolver alguma atividade passo a passo para que os alunos pudessem acompanhar a explicação e as representações que estavam sendo utilizadas pelo estagiário.

Com todas as condições e restrições impostas no desenvolvimento da disciplina, 


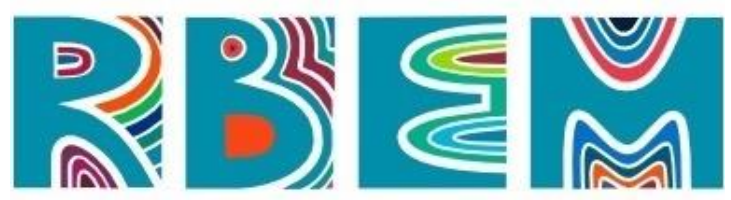

REVISTA BAIANA DE EDUCAÇÃO MATEMÁTICA

podemos visualizar pelos relatos dos acadêmicos o quanto vivenciar a disciplina nesses moldes foi enriquecedor para as suas formações, como mencionam

[...] Esse cenário ganhou uma nova configuração em 2020, desde que começou a pandemia do novo corona vírus, realmente não foi fácil foi um grande desafio ser pioneiro nesta nova modalidade de ensino hibrido nunca antes vivenciado, mas podemos dizer que tem sido de grande valia para a produção de novos conteúdos e utilização de novas ferramentas e tecnologias para o ensino. (E.D.E., 2020).

[...] Este Estágio foi anômalo em relação aos outros pois estamos enfrentando uma pandemia mundial. Acredito que esta foi uma oportunidade única de vivenciarmos a educação de uma maneira nunca vista ou vivida, e estar nesta posição neste momento nos mostrou as possíveis dificuldades que professores enfrentam. (N.O. S., 2020).

[...] nossos encontros discutimos diversos temas e levantamos várias situações, uma delas foi a representatividade do professor na sala de aula, onde ele deixa de ser a figura de "detentor do saber" para a figura do mediador do conhecimento, imaginamos situações hipotéticas na sala de aula com isso a turma de estágio se deparou com vária possibilidade, (V. H., 2020).

Nas falas dos alunos vemos que o modo como foi organizado o plano de estágio dessa

turma, diante das restrições que foram impostas, permitiu que eles vivenciassem algumas situações importantes para a formação desse futuro professor de matemática. Foi uma inciativa emergencial, mas que acabou evidenciando outras possibilidades para se pensar na construção das disciplinas de estágios. Todavia, concordamos que:

[...] o estágio remoto foi uma estratégia pedagógica para a continuidade do curso frente ao fechamento físico das escolas, medida tomada para o enfrentamento da crise imposta pela COVID-19. Porém, destacamos que não há comparação entre a prática do estágio presencial daquela mediada por tecnologias digitais. São experiências totalmente distintas, desde o ponto de vista da mediação pedagógica entre professores e alunos do ensino médio, passando pela transposição didática (CHEVALLARD, 2013) [...] a prática do estágio de forma presencial nas escolas é insubstituível, ainda que tenhamos que considerar que a concepção de estágio deve ser ampliada, englobando outras experiências como esta dedicada a pensar a educação mediada por tecnologias. (CIGALES e SOUZA, 2021, p. 307).

Nesse aspecto, vimos que a implementação da disciplina de estágio via ensino remoto, uma restrição imposta por uma situação emergencial, se mostrou um espaço rico para estudo. Pois, acabou evidenciando outras possibilidades para se pensarmos na construção das disciplinas de estágios. 


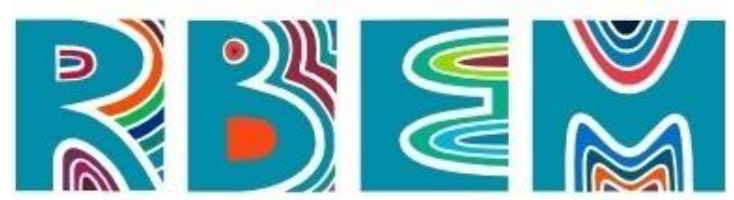

REVISTA BAIANA DE EDUCAÇÃO MATEMÁTICA

\section{Considerações Finais}

O Estágio é um momento importante na formação do futuro professor, e que envolve muito mais do que colocar na prática a teoria. É um momento de trocas, diálogo, reflexão e estudo em torno das diferentes situações e demandas que envolvem o ambiente escolar. Nessa vertente, estar na escola é essencial para vivenciar a realidade desse ambiente. No entanto, até o momento (antes da pandemia) tínhamos como impossível desenvolver o estágio sem estar na escola, e diante do cenário pandêmico, a restrição de aulas presenciais, fez com que toda a educação fosse repensada, pois a vida escolar não podia parar. Assim, mesmo com essas restrições impostas pela pandemia, foi possível criar condições para que os estudantes aprofundassem seus conhecimentos em aspectos importantes para formação inicial de um professor de matemática. Como o uso de tecnologias, tanto para o ensino de conceitos matemáticos por meio de um software, de jogos virtuais, etc. Como também, um meio para ministrar uma aula, no caso a organização e implementação de uma aula síncrona utilizando alguma plataforma como o Google Meet, por exemplo. Além da elaboração de aulas gravadas, seja para apresentação de conceitos, bem como para resolução de atividades. Essas práticas se mostraram importantes não somente por contribuir no processo de construção e domínio dos conteúdos matemáticos e das ferramentas técnicas, mas principalmente pelas discussões e reflexões que permearam todo o processo. Envolvendo a elaboração, a apresentação e a avaliação das atividades realizadas. Possibilitando ao acadêmico refletir sobre suas produções e também sobre as de seus colegas, compreendendo que é importante se preparar para ministrar aulas seja no presencial ou no ensino remoto.

As outras atividades desenvolvidas na disciplina, como: estudo do PPP; análise do livro didático e as aulas simuladas, proporcionaram momentos ricos de discussão e reflexão sobre o ambiente escolar e sobre os recursos disponíveis para o uso em sala de aula. Fazendo com que os acadêmicos pudessem compreender aspectos importantes do funcionamento escolar (Como as normas e o regimento escolar); como também de realizar uma análise crítica frente aos recursos utilizados em sala de aula, principalmente o livro didático, e da diversidade de condições e restrições que interferem diretamente na prática do professor em sala de aula. 


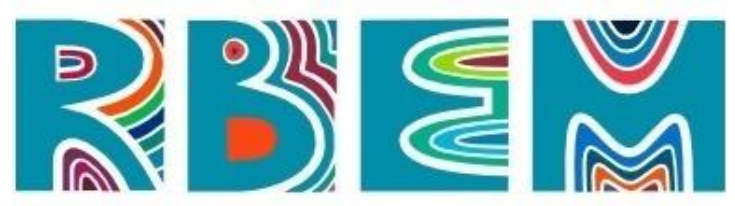

REVISTA BAIANA DE EDUCAÇÃO MATEMÁTICA

As restrições impostas ao desenvolvimento do componente curricular do Estágio Supervisionado II fizeram com que toda a disciplina fosse repensada e analisada de forma diferenciada. Segundo os relatos dos acadêmicos, a disciplina contribuiu para entender e compreender alguns momentos que compõem o ambiente escolar. Logicamente, faltando uma parte essencial na formação desses acadêmicos que é a vivência em uma escola. Todavia, mesmo diante das restrições que fomos submetidos, e com as condições suscitadas, foi possível de trabalhar eem alguns aspectos importantes que permeiam o ambiente escolar e que contribuem para a formação inicial.

Um fato importante no desenvolvimento da disciplina, foi da professora formadora já ter experiência com aulas em ambientes virtuais, isso possibilitou incluir na efetivação da disciplina recursos que facilitassem a interação entre os acadêmicos e a formadora, ocasionando espaços ricos de discussões e reflexões sobre a prática pedagógica. Vale ressaltar que esses acadêmicos foram submetidos a essa restrição institucional, pois não tinham outras opções para cursar a disciplina, independentemente se possuíam ou não recursos tecnológicos para o desenvolvimento da mesma. Isso mostra o quanto tal restrição pode ter ocasionado a desistências de muitos acadêmicos em situações desfavoráveis ao cenário pandêmico, que futuramente precisa ser investigado.

\section{Referências}

BURIGATO, S. M. M. S.; MONGELLI, M. C. G. Como Foi Fazer Um Curso de Licenciatura em Matemática na Modalidade a Distância: Visão dos Primeiros Formandos do Curso de Matemática da UFMS. In: ROCHA, P. G. (Org.). 10 Anos da Educação a Distância na UFMS: A Experiência das Licenciaturas. Porto Alegre, RS: Editora Fi, 2018, p. 251-270.

CHEVALLARD, Yves. Les processus de transposition didactique et leur théorisation. In: Contribution à l'ouvrage dirigé par G. Arsac, Y. Chevallard, J.-L. Martinand, Andrée Tiberghien (éds), La transposition didactique à l'épreuve, La Pensée sauvage, Grenoble, p. 135-180, 1994.

CHEVALLARD, Yves. La notion d'ingénieriedidactique, unconcept à refonder; ClermontFerrand, 16-23 août 2009a. Disponível em http://yves.chevallard.free.fr. Acesso em agosto de 2017.

CHEVALLARD, Yves. Didactique et formation des enseignants, p. 1-20, 2009b. Disponível em http://yves.chevallard.free.fr. Acesso em agosto de 2017. 


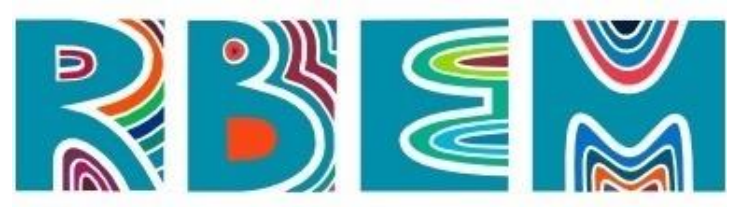

REVISTA BAIANA DE EDUCAÇÃO MATEMÁTICA

CHEVALLARD, Yves. Recherches em didactique et pratiques de formation d'enseignants. février 2002. Notes pour un exposé fait à Namur, dans le cadre des Facultés universitaires Notre-Dame de laPaix, le 5 février 2002. Disponível em:

http://yves.chevallard.free.fr/spip/spip/IMG/pdf/Recherches_en_didactique_et_formation.pdf. Acesso em janeiro de 2018.

CHEVALLARD, Yves. Passé et présent de la théorie anthropologique du didactique. 2007. Disponível em http://yves.chevallard.free.fr/spip/spip/article.php3?id_article=134. Acesso em janeiro de 2018 .

CIGALES, Marcelo Pinheiro; SOUZA, Rodrigo Diego. O Estágio Curricular Supervisionado em tempos de pandemia: um debate em construção. Revista Latitude, v.15, edição especial, p. 286-310, jan., 2021.

FREITAS, Maria Ester. Viver a tese é preciso! Reflexões sobre a aventura e desventuras da vida acadêmica. RAE - Revista de Administração de Empresas, São Paulo, v. 42, n.1, p. 8893, jan./mar. 2002.

MIZUKAMI, Maria da Graça Nicoletti [et al]. Escola e aprendizagem da docência: processos de investigação e formação. São Carlos - EduUFSCAR, 2002.

PIMENTA, Selma Garrido; LIMA, Maria Socorro Lucena. Estágio e docência: diferentes concepções. Revista Poíesis, v. 3, n. 3-4, p. 5-24, 2005/2006.

SANTOS, Cintia Melo dos. Análise da prática pedagógica de uma professora indígena voltada para a Geometria no Ensino Médio. Dissertação (Mestrado) - Programa de PósGraduação em Educação Matemática, Universidade Federal do Mato Grosso do Sul, Campo Grande, 2013.

UNIVERSIDADE FEDERAL DE MATO GROSSO DO SUL (UFMS). Projeto Pedagógico do Curso (PPC) de Matemática - Licenciatura. Instituto de Matemática (INMA), Campo Grande, 2019.

Artigo submetido em: 30/07/2021

Artigo aceito em: 09/10/2021 